\title{
Derleme
}

\section{Ortodontide indirekt yapıştırma tekniği}

\author{
Kübra Yıldırım, * Banu Sağlam Aydınatay \\ Ortodonti Anabilim Dalı, Hacettepe Üniversitesi Diş Hekimliği \\ Fakültesi, Ankara, Türkiye
}

\section{ÖZET}

Sabit ortodontik elemanların, bantlara gereksinim olmaksızın doğrudan dişler üzerine yapıştırıldığı 'Direkt Yapıştırma Tekniği' ile braketleme için klinikte harcanan süre kısaltılmış, daha estetik ve hijyenik bir ortodontik tedavi uygulama imkanı elde edilmiştir. Ancak bu teknikte, özellikle arka dişlere doğrudan görüş ve ulaşım sorunu gibi sebeplerle braket konumlarında hatalarla karşılaşılmıştır. Bu hataların önlenmesi amacıyla 'Indirekt Yapıştırma Tekniği' geliştirilmiştir. Bu tekniğin ilk geliştirildiği yıllarda gözlenen direkt yapıştırılan braketlere kıyasla bağlanma dayanımının daha az olması, yüksek braket kopma oranları, braketlerin etrafından taşan adezivlerin periodontal dokuları irrite etmesi ve oral hijyeni olumsuz etkilemesi, laboratuvar aşamasının uzun ve zaman alıcı olması gibi pek çok olumsuz özelliği günümüzde geliştirilen materyaller ve tekniklerle birlikte elimine edilmiştir. Günümüzde indirekt teknik ile yapıştırılan braketler, direkt yapıştııılan braketlerle benzer bağlanma dayanımı göstermektedir. Ayrıca indirekt ve direkt yapıştırma tekniklerinin, periodontal dokular üzerine etkileri de benzerdir. Ancak indirekt yapıştırma tekniği, hem laboratuvar hem de klinik aşamalarında daha fazla özen ve hassasiyet gerektirmektedir ve maliyeti daha yüksektir. Hekimin bu iki yapıştırma yönteminden hangisini seçeceği; laboratuvar süresi, klinik süresi, maliyet, hasta konforu gibi etkenler ve kendi kişisel tercihine bağlı olarak değişebilir.

Anahtar Kelimeler: Diş yapıştırma; ortodontik adezivler; ortodontik braketler

KAYNAK GöStermek İçin: Yıldırım K, Sağlam Aydınatay B. Ortodontide indirekt yapıştırma tekniği. Acta Odontol Turc 2016;33(3):153-60

ЕрітӧR: Nilüfer Darendeliler, Gazi Üniversitesi, Ankara, Türkiye

YAYıN HAKKı: @ 2016 Yıldırım ve Sağlam Aydınatay. Bu eserin yayın hakkı Creative Commons Attribution License ile ruhsatlandırılmıştır. Sınırsız kullanım, dağııım ve her türlü ortamda çoğaltım, yazarlar ve kaynağın belirtilmesi kaydıyla serbesttir.

[Abstract in English is at the end of the manuscript]

Makale gönderiliş tarihi: 17 Haziran 2015; Yayına kabul tarihi: 21 Kasım 2015 * letiş̧im: Kübra Y̌ldııım, Ortodonti Anabilim Dalı, Hacettepe Üniversitesi Diş Hekimliği Fakültesi, Sıhhiye, Ankara, Türkiye;

E-posta: kbr.yalcin@gmail.com

\section{Giriş}

Dişleri düzgün şekilde sıralayabilmek için kullanılan hareketli apareylerden, sabit apareylere geçiş ortodonti tarihinde önemli bir aşama olmuştur. Sabit elemanlar olan braketler ve tüpler başlangıçta hastanın dişleri üzerine bantlar aracılığı ile yapıştııımıştır. Bu yöntemin en büyük sakıncası, bantlar dişlere yapıştırıldığında braketlerin dişler üzerinde her zaman doğru konumda yerleştirilememesidir. 1970'lerde meydana gelen iki gelişme sabit apareylerin geleceğini değiştirmiş̧tir. Bunlardan ilki daha detaylı diş hareketi sağlayabilen torklu ve açılı braketlerin geliştirilmesi, bir diğeri ise braketleri dişler üzerine yapıştııırken bantlara gereksinimi ortadan kaldıran direkt yapıştırma tekniğinin tanıtılmasıdır.

Direkt yapıştırma tekniğinin geliştirilmesi ile hekimler, braketleri daha kısa sürede yapıştırma imkanı bulmuşlardır. Ayrıca hastaların ağız bakımlarını daha rahat bir şekilde gerçekleştirmeleri sağlanmıştır. Ancak, arka dişlerde görüş ve ulaşım problemleri sebebiyle braket konumlarında hatalarla karşılaşılmıştır.

Bu hataları önleyecek 'Indirekt Yapıştırma Tekniği' 1970'lerin başlarında geliştirilmiştir. 'Direkt Yapıştırma Tekniği'nden' farklı olarak 'Indirekt Yapıştırma Tekniği' iki aşamalıdır. Laboratuvar aşamasında braketler, hastadan alınan ölçülerden elde edilen alçı modeldeki dişler üzerine uygun şekilde yerleştirilir ve model üzerinde aktarma kaşığı hazırlanır. Klinik aşamada ise bu kaşık içindeki braketler hastanın dişlerine yapıştırılır. Bu teknik daha çok lingual sabit ortodontik apareylerin yapıştırılmasında tercih edilmekle birlikte lingual retainer yapıştııımasında ve daha doğru braket konumu sağladığı için labial sabit ortodontik apareylerin yapıştırılmasında da kullanılmaktadır. Bu makalede indirekt yapışııma tekniği ile ilişkili literatür incelenerek, tekniğin klinik kullanımında önemli faktörler değerlendirilecektir.

\section{İndirekt yapıştırma tekniği}

'Bonding' kavramı 1955'te Buonocore ${ }^{2}$ tarafından diş hekimliğine tanıtılmış ve bu gelişme, braketleri dişler üzerine yapıştıırken bantlara gereksinimi ortadan kaldıran direkt yapışıırma tekniğinin de temellerini oluşturmuştur.

Direkt yapıştırma tekniği için 1970'lerin başlarında pek çok adeziv geliştirilmiştir. ${ }^{3,4}$ Buonocore'un ${ }^{2,4}$ geliştirdiği acid-etch ile bis-GMA rezinin birlikte uygulandığı sistem, Silverman ve ark. ${ }^{3}$ ve Weisser ${ }^{5}$ tarafından braketleri yapıştırmak için kullanmıştır. 
Direkt yapıştırma tekniğinin geliştirilmesi ile braketleme için klinikte harcanan süre kısaltılmış, braketlerin bantlara oranla diş üzerinde daha az yer kaplaması sonucu hem daha estetik hem de daha hijyenik bir ortodontik tedavi uygulama şansı elde edilmiştir., ${ }^{6,7}$ Ayrıca, bu teknikte kullanılan kimyasal sertleşen rezinlere alternatif olarak üretilen ışıkla sertleşen rezinler, uzun olan çalışma süreleri sayesinde braketleme sırasında bir diş üzerine yerleştirilen braketin konumunun doğruluğunu kontrol etmek için ortodontiste zaman kazandırmıştır. Ancak, arka dişleri doğrudan görmek mümkün olmadığı için braketleri bu dişlere uygun ve doğru şekilde yerleştirmek sorun oluşturmuştur.

Bu soruna çözüm getirebilecek indirekt yapıştırma tekniği ise ilk olarak 1972 yılında, Silverman \& Cohen $^{8}$ tarafından tanıııımıştır. 'Direkt Yapıştırma Tekniğg'nden farklı olarak 'İndirekt Yapıştırma Tekniğg' iki aşamalıdır. Laboratuvar aşamasında braketler, hastanın dental modellerindeki dişler üzerine uygun şekilde yerleştirilir (Resim 1). Daha sonra modeller üzerinde aktarma kaşığı hazırlanır (Resim 2, 3). Klinik aşamada ise bu kaşık içindeki braketler hastanın dişlerine yapıştıııır (Resim 4).

Bu tekniği tanıtan yazarlar; farklı tipteki braketleri, farklı adeziv ve rezinler kullanarak yapıştırdıkları çeşitli indirekt yapıştırma yöntemleri geliştirmişlerdir. ${ }^{8}$ Günümüzde en çok kabul gören yöntem ise, 1979 yılında Thomas $^{9}$ tarafından tanıtılan tekniktir. Thomas, ${ }^{9}$ ilk başlarda çalışma modeli üzerinde braketleri konumlandırmak için yumuşak karamel ve bu braketleri hastanın dişleri üzerine yapıştırırken kimyasal sertleşen rezin kullanmıştır. Ancak, yapıştırma sonrasında braketlerin çevresinde aşırı rezin artığı kaldığı ve bu artıkları temizlemek için ekstra bir zaman harcanması gerektiği için kişiye özel rezin braket tabanların hazırlandığı 'Custom Base' indirekt yapıştırma tekniğini geliştirmiştir..$^{9}$ Bu tekniğin laboratuar aşamasında braket tabanlarına kimyasal sertleşen bis-GMA rezin uygulayarak braketleri alçı model üzerindeki dişlere tutturmuştur. Sertleşmeden önce braket kenarındaki rezin artıklarını temizlemiştir. Dişlerin üzerine universal rezin, aktarma kaşığı içindeki braketlerin tabanlarına da katalizör rezin uyguladıktan sonra kaşığı hastanın dişlerine yerleştirmiş ve yapıştırma işlemini tamamlamışı̧ı. Bu yöntemin en büyük sakıncası, iki rezinin teması ile başlayan kimyasal sertleşme tamamlanmadan aktarma kaşığının çıkartılabilmesidir. Bu sakıncayı ortadan kaldırabilmek için 'Modifiye Thomas Yöntemi' geliştirilmiştir. ${ }^{10} \mathrm{Bu}$ yöntemde kullanılan adezivin katalizör ve base rezini, mine ve braket tabanlarına uygulanmadan önce karıştııımakta ve böylece rezinin uygun şekilde sertleşmesi garantilenmektedir.

\section{İndirekt yapıştırma tekniğinin avantaj ve dezavan- tajları}

İndirekt yapıştırma tekniğini tanıtan yazarlar bu tekniğin yararlarını, klinikte braketleme için harcanan zamanın kısaltılması, braketlerin daha doğru bir şekilde yerleş-

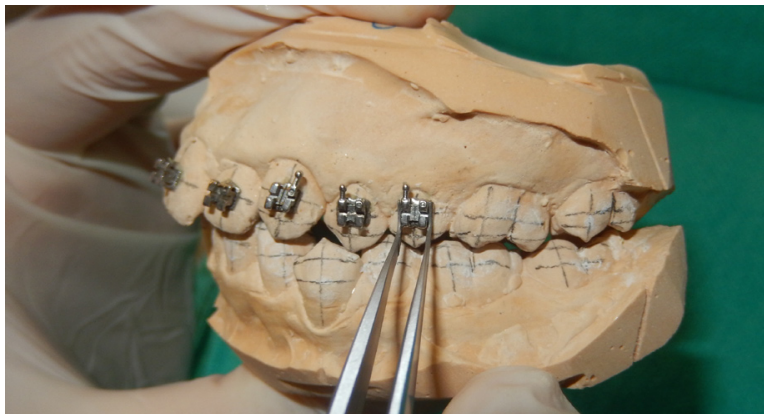

Resim 1. Indirekt yapıştırma tekniği laboratuvar aşaması; braketin model üzerinde konumlandırılması

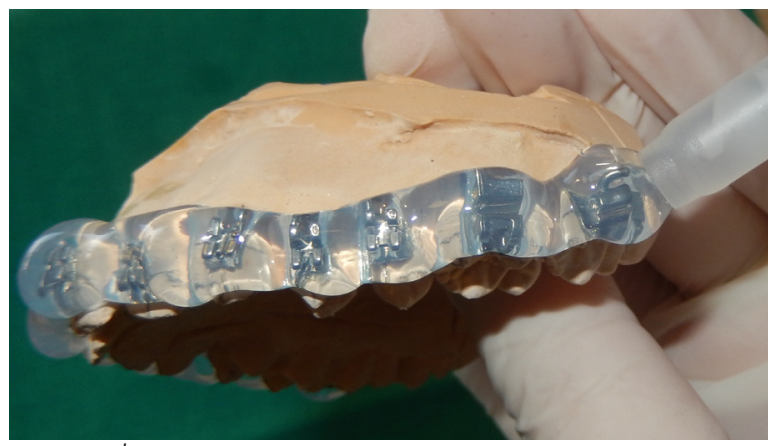

Resim 2. Indirekt yapıştırma tekniği laboratuvar aşaması; aktarma kaşığı yapımı, iç tabaka (şeffaf silikon ölçü maddesi)

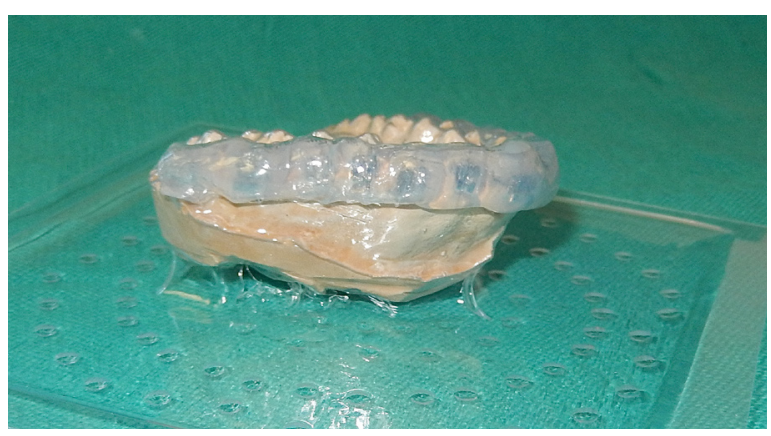

Resim 3. Indirekt yapıştırma tekniği laboratuvar aşaması; aktarma kaşığı yapımı, dış tabaka (termoplastik materyal)

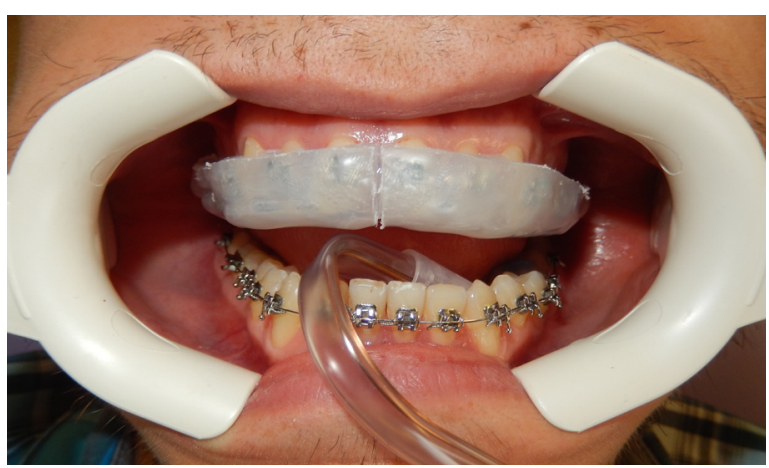

Resim 4. Indirekt yapıştırma tekniği klinik aşaması; braketlerin dişlere yapıştırılması

tirilebilmesi ve braketleme sırasında hasta konforunun artııııması olarak belirtmişlerdir. ${ }^{3}$ Ancak, bu teknikte braketleme öncesinde hazırlık aşaması olması, ${ }^{11}$ hem laboratuvar hem de klinik aşamada daha fazla özen 
gerekmesi, 9,12 aktarma kaşığı içindeki braketleri dişlere yapıştırmak için kullanılan yapıştırıcının braket kenarlarından taşması, taşan yapıştırıcı artıklarını temizlemenin zor ve zaman alıcı olması, ${ }^{1,8,9}$ temizlenemeyen artıkların ağız hijyenini tehdit etmesi ${ }^{12,13}$ ve bu teknikte kullanılan yapıştırıcılar ile braketle diş arasında kuvvetli bir bağlanma elde edilememesi, ${ }^{13}$ araştırmacıları bu tekniği modifiye etmeye yöneltmiştir.

Bu yönde gerçekleştirilen en önemli gelişmeler:

- Laboratuvar aşamasında braketleri alçı dişlere yapıştırmak için kullanılan karamel yerine adezivlerin kullanılmaya başlanması,

- Aktarma kaşığı yapımında, şeffaf ölçü maddeleri ve termoplastik materyallerinden yararlanılmaya başlanması,

- İndirekt yapıştırma tekniğine özel klinik rezinlerin üretilmesidir.

$\mathrm{Bu}$ gelişmeler sonucunda, braket kenarlarından taşan adeziv miktarı azaltılmış ancak tamamen ortadan kaldırılamamış, ${ }^{1,14}$ braketlerin dişlere daha kuvvetli bağlanması sağlanmış fakat direkt yapıştırma tekniği ile elde edilen bağlanma kuvveti seviyelerine ulaşılamamıştır. ${ }^{15}$

Son zamanlarda direkt yapıştırma tekniğinde kimyasal sertleşenlere oranla daha fazla tercih edilen ışıkla sertleşen adezivler indirekt yapıştırma tekniğinde de kullanılmaya başlanmıştır. Böylece tekniğin sakıncalarını azaltan çeşitli yöntemler geliştirilmiştir. ${ }^{8}$ Ancak tüm bu çabalara rağmen, ABD'de ortodontistler arasında yapılan bir çalışma, indirekt yapıştırma tekniğinin direkt yapıştırma tekniğine kıyasla günümüzde ancak \%10 seviyelerinde kullanıldığını ortaya koymuştur. ${ }^{16}$

\section{İndirekt yapıştırma tekniğinin aşamaları ve kullanı- Ian materyaller}

Günümüzde çeşitli indirekt yapıştırma yöntemleri mevcuttur. Bunların çoğu Thomas Tekniği'nin birer modifikasyonudur. ${ }^{12} \mathrm{Bu}$ yöntemlerdeki farklılıklar:

- Laboratuar aşamasında braketlerin alçı modele tutturulması sırasında kullanılan materyallerden,

- Aktarma kaşığının tipinden ve kaşık yapımı sırasında kullanılan materyallerden (tek kat termoplastik, çift kat termoplastik, polivinilsiloksan, polivinilsiloksan + termoplastik, şeffaf silikon + termoplastik),

- Klinikte kullanılan rezinin tipinden ve yapıştırmanın bölümlü ya da tam (tüm ark, bölümlü ark ya da tek diş şeklinde) yapılmasından kaynaklanmaktadır.

\section{Braketlerin alçı modele yapıştırılmasında kullanılan materyaller}

İndirekt yapıştırma tekniğinin laboratuvar aşamasında braketleri alçı modeldeki dişlere yapıştırırken ilk zamanlarda karamel, ${ }^{8,9}$ yapışkan mum ve yapıştırıcı tutkal kullanıımıştır. ${ }^{11} \mathrm{Bu}$ materyallerin yararı, aktarma kaşığı yapımından sonra model suda bekletildiğinde çözünmeleri ve diğer pek çok indirekt yapıştırma tekniğinden farklı olarak braket tabanına herhangi bir işlem uygulaması gerektirmemeleridir. Ancak, bu materyaller ile alçı modele yapıştıılan braketler hasta ağzına aktarılırken suda erimiş olan karamelin ya da tutkalın yerine konan kompozit rezin dişlere bulaşmış ve hem rezin miktarının azalmasına hem de meydana gelen çapaklanmanın artmasına neden olmuştur. ${ }^{9,17}$ Azalan rezin miktarına bağlı olarak braketler dişlere daha az kuvvetle bağlanmış, ${ }^{17}$ yapıştırma sonrasında braketlerin çevresinde kalan aşırı rezin artıklarını temizlemek de daha fazla zaman gerektirmiştir. ${ }^{1,9,17}$ Bunun için Thomas, ${ }^{9}$ karamel yerine kimyasal sertleşen kompozit rezin kullanımını önermiştir. Ancak, günümüzde laboratuvar rezini olarak genellikle ısıyla ${ }^{14}$ ya da ışıkla ${ }^{1,18}$ sertleşen rezinler tercih edilmektedir. Isıyla sertleşen rezin, braketleri yerleştirme sırasında sınırsız çalışma süresi tanır ancak ısı uygulandığında braketlerin alçı diş üzerinde kayarak yer değiştirme riski söz konusudur..$^{1,19}$ Işılkla sertleşen kompozit rezin kullanıldığında ise braketler alçı model üzerine hızlı ve etkili bir biçimde yerleştirilebilmektedir. $\mathrm{Bu}$ amaçla tabanı adeziv kaplanmış 'APC (Adhesive Precoated Brackets)' braketler kullanıldığında ise rezinin kontaminasyonu engellenebilir ve laboratuvar süresi minimuma indirilebilir. ${ }^{1}$ Bunun nedeni; braketleri alçı dişler üzerine yerleştirirken braket tabanlarına kompozit rezin uygulama gerekmemesi ve böylece laboratuvarda harcanan zamanın azalmasıdır.

\section{Aktarma kaşığı yapımında kullanılan materyaller}

Bu teknikte kullanılan aktarma kaşıkları iki ana gruba ayrılabilir:20

\section{Tüm-ark kaşıkları}

- Opak silikon aktarma kaşıkları (Reprosil LD Caulk Division; Dentsplay International, Milford, DE, ABD, Exaflex; GC America, Alsip, IL, ABD)

- Şeffaf silikon aktarma kaşıkları (Memosil; Heraeus Kulzer, Hanau, Hessen, Almanya, Emiluma; Opal Orthodontics, South Jordan, UT, ABD)

- Termoplastik aktarma kaşıkları (Biocryl; Great Lakes Orthodontics, Tonowanda, NY, ABD, Bioplast; Great Lakes Orthodontics, Essix; Raintree Essix Inc, New Orleans, LA, ABD)

Tek-diş kaşıkları

- 'Hiro' Sistemi21

- 'Hybrid Core' Sistemi22

- Kyung'un indirekt yapıştırma için geliştirdiği bireysel kaşıklar ${ }^{23}$

- Kim'in geliştirdiği 'Convertible Resin Core (CRC)'
kaşıklar'24,25

Aktarma kaşıkları bir çenedeki tüm dişleri içeren kaşıklar ve tek bir dişi içeren kaşıklar olarak ayrılabilir. Aktarma kaşığı yapımında genellikle opak silikon ölçü 
maddeleri, şeffaf silikon ölçü maddeleri ve termoplastik materyallerden yararlanılmaktadır. ${ }^{20}$

Opak silikon ölçü maddesinden yapılmış kaşıkları, yapıştırma işlemi tamamlandıktan sonra hasta ağzından uzaklaştırmak zordur. Çünkü bu materyal braket kulakçıklarının ve slotunun oluşturduğu girintilerden kolayca çıkabilecek kadar elastik değildir. Ayrıca, opak silikon ölçü maddesinden hazırlanan kaşıklar ile birlikte ışıkla sertleşen rezin kullanılamaz ve kaşık dişler üzerine yerleştirildikten sonra braketlerin dişler üzerindeki konumunun doğruluğu kontrol edilemez. ${ }^{20,26}$

Opak silikondan hazırlanan kaşıklarda karşılaşılan problemler şeffaf silikon ölçü materyali kullanılarak elimine edilebilir. Koga ve ark. ${ }^{27}$ çift kat şeffaf silikon aktarma kaşığını tanıtmışlardır. Kaşığın alt tabakasında; braketlerin oluşturduğu girintilerden kolaylıkla çıkabilecek esnekliğe sahip yumuşak kıvamlı şeffaf silikon kullanılırken, üst tabakası kaşığın formunun bozulmasını engelleyen sert şeffaf silikondan hazırlanmaktadır.

Aktarma kaşığı yapımında kullanılan bir diğer materyal de termoplastiklerdir. Daha ince ve esnek yapıya sahip 'Bioplast', 'Biocryl' gibi termoplastik materyallerden tek tabakadan oluşan aktarma kaşıkları hazırlanabilmektedir. Ancak sadece bu materyallerden yapılan kaşıklar deformasyona karşı dayanıksız olup braket transferinde hatalara, diş ve braket arası bağlantının zayıflamasına neden olabilir. Daha sert yapıya sahip olan 'Essix' plakları ise çift tabakalı kaşıkların dış kısmının yapımında kullanılmaktadır. ${ }^{28}$

Indirekt yapıştırma tekniğinde rutin olarak kullanılan bu kaşıklardan farklı olarak 2006 yılında, hızlı prototiplenmiş aktarma kaşıkları (RPT) tanıtılmıştır. ${ }^{29}$ Bu kaşıkların hazırlanmasında CAD/CAM sisteminden faydalanılmaktadır. Öncelikle alçı modeller üç boyutlu tarayıcılar ile taranır ve görüntüleri bilgisayar ortamına aktarılır. Bu görüntü üzerinde her diş için uygun braketler seçilir ve diş üzerine ideal konumu ayarlanarak yerleştirilir. Bütün braketler yerleştirildikten sonra hızlı prototiplenmiş kaşık yapımına geçilir. Bu kaşıklar tek diş, bir grup diş veya tüm ark için yapılabilir. Kaşıklar yarı-elastik plastik şeffaf materyalden yapılır. Böylece, braketler dişler üzerine yapıştırılırken ışıkla sertleşen rezin kullanılabilir. ${ }^{29}$

Günümüzde aktarma kaşığı yapımında kullanılan çoğu teknik temelini; Hickham ${ }^{10}$ tarafından geliştirilen, 'Dual Clear Tray System'den almaktadır. Bu sistemde transfer kaşığı iki tabakadan oluşmaktadır. İç tabaka yumuşak şeffaf silikon ölçü maddesinden hazırlanmakta, dış tabaka ise sert termoplastik materyalden hazırlanmaktadır (Resim 5).

Castilla ve ark. ${ }^{30} 2014$ yılında yapmış oldukları çaışmalarında, bahsedilen bu kaşıkların braketleri dişler üzerine doğru bir şekilde aktarıp aktarmadığını araştırmışlardır. Çalışmada, beş farklı aktarma kaşığının kullanıldığı indirekt yapıştırma teknikleri, braket transferi doğruluğu açısından karşılaşılaştırılmıştır. Çift kat şeffaf silikon, çift kat termoplastik, light body opak silikon +

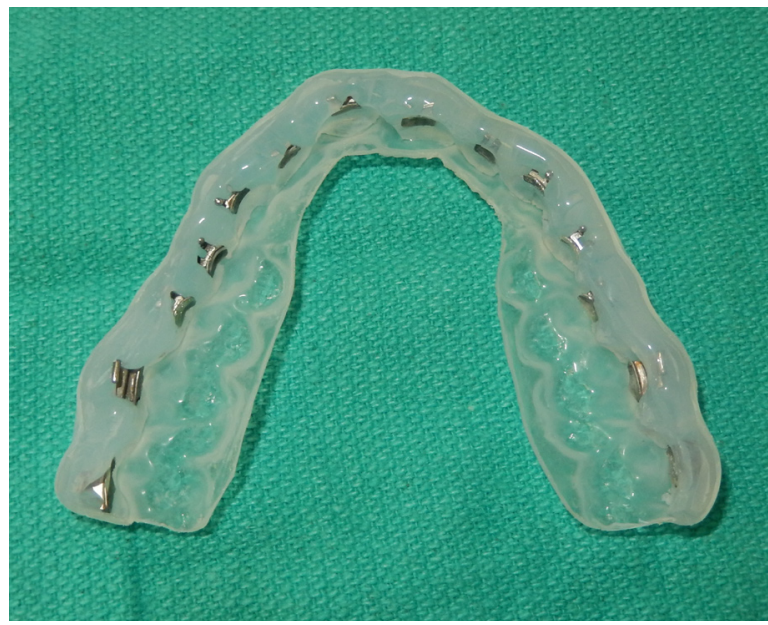

Resim 5. Dual clear tray; iç tabaka: şeffaf silikon ölçü maddesi, dış tabaka: termoplastik materyal

termoplastik, tek kat opak silikon ve tek kat termoplastikten hazırlanan 5 ayrı kaşık karşılaştırılmıştır. Sonuç olarak, tek kat veya çift kat termoplastik materyallerden hazırlanan kaşıklarda, braketlerin dişlere transferi esnasında özellikle okluzogingival yönde daha çok hatayla karşılaşıldığı gösterilmiştir. ${ }^{30}$

\section{Klinik aşamada kullanılan rezinler}

İndirekt yapıştırma tekniğinde 2000'lerin başlarına kadar klinik rezin olarak, direkt yapıştırma tekniği için geliştirilmiş, kimyasal'10,12,14,31 veya ışıkla ${ }^{1,12,18,32}$ sertleşen rezinler kullanılmıştır. Bu rezinler indirekt yapıştırma tekniğinin gereksinimlerini tam anlamıyla karşılayamadığı için hep tekniğe uygun hale getirilmeye çalışılmıştır. Sondhi, ${ }^{1}$ bu eksiği fark etmiş ve 3M Unitek (3M Dental Products, St. Paul, MN, ABD) firmasının yardımıyla indirekt yapıştırma tekniği için kimyasal sertleşen bir klinik rezin geliştirmiştir. Bu rezinin özelliği, içeriğine silika parçacıkları eklenerek yoğunluğunun yaklaşık \%5 arttırılmış olmasıdır. Böylece, braket tabanında meydana gelebilecek hava boşluklarını dolduracak, rezin tabakada oluşabilecek eksiklikleri tamamlayacak ve braket tabanı üzerinden akmayacak kadar akışkan bir rezin üretilmiştir. ${ }^{1,5}$ Günümüzde indirekt yapıştırma tekniği için geliştirilmiş iki sistem mevcuttur. ${ }^{9}$ Birincisinde braketler alçı model üzerindeki dişlere ısı ile sertleşen kompozit rezinle (Therma Cure; Reliance Orthodontics, Itasca, IL, ABD) yapıştırılmakta, hazırlanan transfer kaŞık içindeki braketler hastanın dişlerine yapıştırılırken kimyasal sertleşen rezinle (Custom IQ; Reliance Orthodontics) birlikte yapışmayı arttırmak amacıyla Enhance (Reliance Orthodontics) kullanılmaktadır. Diğer sistemde ise braketler alçı model üzerindeki dişlere ışıkla sertleşen kompozit rezinle (Transbond XT; 3M Unitek) yapıştırılmakta, hazırlanan aktarma kaşığı içindeki braketler hastanın dişlerine yapıştırılırken kimyasal sertleşen rezin ya da ışıkla sertleşen akıcı kompozit (Transbond Supreme LV Low Viscosity Light Cure Adhesive, 3M Unitek) kullanılmaktadır. 


\section{İndirekt ve direkt yapıştırma tekniklerinin karşılaş- tırılması}

\section{Bağlanma dayanımları ve braket kopma oranları}

Bu konuda yapılmış birçok in vitro ve in vivo çalışma vardır. 2003 yılın yapılan bir in vitro çalışmada indirekt yapıştırma tekniği için önerilen çeşitli adezivler ile direkt yapıştırma tekniği için kullanılan 'Transbond XT'nin bağlanma dayanımları karşılaştırılmıştır. Bunun için 100 adet kesici diş her bir grupta 20'şer diş olacak şekilde 5 gruba ayrılmıştır. İlk dört grupta indirekt yapıştırma tekniği uygulanmıştır. Grup 1 ve 4'te modifiye Thomas tekniği kullanılırken, grup 2 ve 3'te Thomas tekniği kullanılmıştır. Grup 5'te ise direkt yapıştırma tekniği uygulanmıştır (Grup 4'te kullanılan yapıştırıcılar kimsayal sertleşen kompozit ve sealanttır.). Sonuç olarak grup 3,4 ve 5 diğer gruplara göre daha yüksek ve birbirleriyle benzer bağlanma dayanımı göstermiştir. Grup 1 ve 2'de kullanılan ısı ile sertleşen rezinler ile bağlanmada daha yüksek oranlarda başarısızlıkla karşılaşılabileceği gözlenmiştir. ${ }^{33}$

Işıkla sertleşen 'Transbond $\mathrm{XT}$ ' rezinle direkt yapıştırılan braketlerin bağlanma dayanıklılığını, iki farklı indirekt yapıştırma yöntemi kullanılarak yapıştırılan braketlerinki ile karşılaştıran bir başka çalışma mevcuttur. Çalışmada kullanılan indirekt yapıştırma yöntemlerinin birinde; laboratuvar aşamasında ışıkla sertleşen 'Transbond $\mathrm{XT}$ ' rezin, transfer sırasında kimyasal sertleşen 'Sondhi Rapid Set' (3M Unitek) kullanılmıştır. Bir diğerinde ise laboratuvar aşamasında ışıkla sertleşen 'Enlight LV' (Ormco Corporation, Glendora, CA, ABD) rezin, transfer sırasında yine ışıkla sertleşen 'Orthosolo' (Ormco Corporation) primer ile birlikte 'Enlight' LV rezin kullanılmıştır. Bu çalışmada genel olarak ışıkla sertleşen rezinle direkt yapıştırılan braketlerin bağlanma dayanıklılığı ile bu 2 farklı indirekt yapıştırma yöntemiyle yapıştırılan braketlerin bağlanma dayanıklıığı arasında istatistiksel olarak anlamlı bir fark bulunamamıştır. ${ }^{34}$

Yukarıda bahsedilen çalışmalarda tek dişi içeren aktarma kaşıkları kullanıımıştır. 2004 yılında Polat ve arkadaşlarının ${ }^{15}$ yapmış olduğu çalışmada ise tüm arkı içeren aktarma kaşıkları kullanılmış ve laboratuvar aşamasında ısı ile sertleşen 'Therma Cure' rezin + klinik aşamada 'Custom IQ' ile laboratuvar aşamasında ışık ile sertleşen Transbond XT + klinik aşamada 'Sondhi Rapid' Set kullanılan indirek yapıştırma teknikleri in vitro olarak braket bağlanma dayanıkılığı yönünden karşılaştırılmıştır. Sonuç olarak ısı ile sertleşen 'Therma Cure' rezin + 'Custom IQ' kullanılan indirekt yapıştırma tekniğinde bağlanma dayanımı daha yüksek bulunmuştur. Bu çalışmada ayrıca karşılaştırılan bu iki indirekt yapıştırma yöntemi ile braketlenen 15 hasta 9 ay boyunca klinik olarak braket kopması yönünden değerlendirilmiş ve iki teknik arasında anlamlı bir fark bulunamamıştır. ${ }^{15}$

Direkt ve indirekt yapıştırma tekniklerini bağlanma dayanımları açısından karşılaştıran çalışmaların çoğunda braket-adeziv-mine ara yüzünde meydana gelen kopmanın yeri ve bağlanma dayanımı ile ara- sındaki ilişki belirlenmeye çalışılmıştır. Braket kopması sonrasında diş üzerinde kalan adeziv miktarı Årtun ve Bergland $^{35}$ tarafından geliştirilen ARI (Adhesive Remnant Index [Artık Adeziv İndeksi]) skorlamasına göre değerlendirilmiştir. Bu skorlamada 0 , diş üzerinde hiç adeziv artığı kalmadığını; 1, diş üzerinde kalan adeziv artığının \%50'den az olduğunu; 2, diş üzerinde kalan adeziv artığının \%50'den fazla olduğunu; 3 ise tüm adezivin diş üzerinde kaldığını ifade etmektedir. Genel olarak çalışmalar incelendiğinde hem direkt hem de indirekt yapıştırma yöntemlerinde skorların 1 ve 2 arasında yoğunlaştığı yani kopmanın koheziv olduğu dikkat çekmektedir. ${ }^{35-37}$ Ancak bu çalışmalarda kullanılan yapıştırma materyallerinin, uygulanan kuvvet değerlerinin ve rezin braket tabanını bekletme sürelerinin farklı olması kopma bölgesi açısından kesin bir yargıya varmayı zorlaştırmaktadır. Bağlanma dayanımı ile kopma bölgesi arasındaki ilişkiyi inceleyen çalışmaların sonucunda da bu iki değişken arasında bir ilişki olmadığı ortaya çıkarılmıştır. ${ }^{37-39}$

Braket kopması ve bağlanma dayanımını inceleyen in vivo çalışmalarda genel olarak, braketlemeyi takiben 6 aylık süre içinde braket kopma oranları değerlendirilmiştir. ${ }^{13,40,41}$ İndirekt yapıştırma tekniğinin henüz yeni kullanılmaya başlandığı 1978 yılında yapılan bir çalışmada kimyasal sertleşen Concise (3M Unitek) ve Endur (Ormco Corporation) rezinle direkt yapıştırılan braketlerin kopma oranı \%2.5, laboratuvarda karamel, klinikte kimyasal sertleşen Auto-Tach (LD Caulk Company, Milford, DE, ABD) ve Endur rezin kullanılarak indirekt yapıştırılan braketlerin kopma oranı ise \%13.9 bulunmuştur. ${ }^{13}$ İndirekt yapıştırma tekniğindeki bu yüksek kopma oranları laboratuar ve klinik aşamada kimyasal sertleşen rezin kullanıldığında \%4.5'e, ${ }^{42}$ laboratuvar ve klinik aşamada ışıkla sertleşen Opalux (ICI Dental, Macclesfield, İngiltere) rezin kullanıldığında \%6.5'e kadar gerilemiştir. ${ }^{43}$ İndirekt yöntemle yapıştırılan braketlerde erken okluzal temasların varlığında okluzyon yükseltici kullanılan iki çalışmadan birincisinde laboratuvar aşamasında ışıkla sertleşen 'Light Bond' (Reliance Orthodontics) rezin, klinik aşamada kimyasal sertleşen 'Maximum Cure' (Reliance Orthodontics) rezin kullanılarak yapıştırılan braketlerin kopma oranı \%1.4 olarak kaydedilmiştir. ${ }^{40}$ Laboratuvarda APC braketlerle hazırlanan rezin braket tabanlarının klinik aşamada ışıkla sertleşen 'Filtek Flow' (3M, Unitek) rezinle yapıştırıldığı ikinci çalışmada ise braket kopma oranı \%1.3 bulunmuştur. ${ }^{41} \mathrm{Bu}$ çalışmalardan farklı olarak plastik ve metal braketlerdeki kopma oranlarının karŞılaştırıldığı bir çalışmada ise özellikle plastik braketlerde, ışıkla sertleşen rezinle hazırlanan rezin braket tabanlarının, ısıyla sertleşen rezinle hazırlanan rezin braket tabanlarından daha kuvvetli bir bağlanma sağladığı ortaya çıkarılmıştır. ${ }^{44}$ Read ve arkadaşlarının ${ }^{43}$ üst ve alt çenede ve ön ve arka diş gruplarında kopma oranlarındaki farkı araştıran çalışmasında ne üst ve alt çeneler arasında ne de ön ve arka diş grupları arasında istatistiksel olarak önemli bir fark bulunamamıştır. Yine aynı çalışmada braket kopma zamanı incelendiğinde 
kopan tüm braketlerin \%13'ünün braketlemeyi takip eden birinci ayda, \%94'ünün ise ilk 6 ayda meydana geldiği bulunmuştur.

Direkt ve indirekt yapıştırma tekniklerinin uygulama süreleri ve braket kopma oranlarını karşılaştıran 17 hastanın katıldığı bir klinik çalışmada braketlerin 151'i direkt, 153'ü indirekt yöntemle yapıştırılmıştır. 24 haftalık takip süresi sonucunda iki teknik arasında braket kopması yönünden anlamlı fark gözlenmemiştir. ${ }^{45}$

İndirekt ve direkt teknik ile yapıştırılan braketlerin kopması yönünden değerlendirilen bir diğer klinik çaIışmada ise her iki yöntemde de braketler dişlere ışıkla sertleşen 'Transbond XT' rezin kullanılarak yapıştırılmış ve hastalar 1 yıl süre ile takip edilmiştir. Sonuç olarak yapıştırılan 553 braketten 14' ünde kopma gözlenmiş ve braket kopma oranı \%2.5 olarak bulunmuştur. İki yöntem arasında braket kopması açısından anlamlı fark bulunamamıştır. ${ }^{46}$

\section{Çalışma süreleri ve toplam tedavi süreleri}

Aguirre ve arkadaşlarının ${ }^{42}$ yapmış olduğu çalışmada indirekt ve direkt yapıştırma teknikleri için harcanan süreler de karşılaştırılmış ve direkt yapıştırma tekniği için gereken ortalama klinik sürenin $42.18 \mathrm{dk}$, indirekt teknikte laboratuvar aşaması için gereken ortalama sürenin $53.73 \mathrm{dk}$, ortalama klinik sürenin ise $23.91 \mathrm{dk}$ olduğu belirtilmiştir.

Bozelli ve arkadaşlarının ${ }^{45}$ yapmış olduğu bir başka çalışmada ise indirekt yapıştırma tekniğinin klinik aşamasının direkt yapıştırma tekniğine göre daha kısa sürdüğü ancak laboratuvar aşaması da dahil edildiğinde daha fazla vakit aldığı belirtilmiştir. Ayrıca bu çalışmada indirekt yapıştırma tekniğinde braketlerin laboratuvarda modeller üzerine konumlandırılması için gereken süre ve klinik aşama için gereken süreler toplamının direkt yapıştırma için gerekli klinik süre ile benzer olduğu belirtilmiştir. ${ }^{45}$

Indirekt ve direkt yapıştırma tekniklerini pratik açıdan karşılaştıran bir retrospektif çalışmada 772'sinde direkt braketleme, 596'sında indirekt braketleme yapılan 1368 hastanın randevu sayıları ve toplam tedavi süreleri karşılaştırılmıştır. Toplam tedavi süreleri ve randevu sayılarının indirekt teknikle braketlenen hastalarda sırasıyla 745 gün ve 22 adet randevu olduğu bulunurken, indirekt hastalarda sırasıyla 745 gün ve 22 adet randevu olduğu bulunmuştur. Sonuç olarak toplam tedavi süreleri yönünden bu iki teknik arası anlamlı bir fark bulunamamıştır. ${ }^{47}$

\section{Braket konumunun doğruluğu}

İndirekt yapıştırma tekniğiyle braketlerin daha ideal konumlandırılacağına ilişkin genel bir görüş olmasına rağmen bu konuyu değerlendiren çok az çalışma mevcuttur. Yapılan çalışmalarda da direkt yapıştırılan ve yerleştirilmesinde zorluğun yaşandığı arka grup dişlerin braketlerinin konumları değerlendirmeye alınmamıştır.

Koo ve ark. ${ }^{48}$ braket konumunun doğruluğu yönünden direkt ve indirekt yapıştırma tekniklerini karşılaş- tıran laboratuvar çalışmalarında; alt ve üst çeneden oluşan bir set dental modelden dublike ettikleri 19 set modeli üç gruba ayırmışlardır. Birinci grup ideal braket konumunu belirlemede kullanılan bir set modeli içermekte iken, ikinci grupta direkt braketleme için 9 set model ve üçüncü grupta indirekt braketleme için 9 set model bulunmaktadır. Dokuz farklı ortodontist 2. ve 3. gruptan birer set modelde molar dişler haricindeki dişlere braketleme yapmıştır. Daha sonra her bir braketleme grubu birbiriyle ve ideal braketleme grubu ile braket yüksekliği, angulasyon ve meziodistal pozisyon açısından karşılaştırılmıştır. Sonuç olarak; angulasyon ve meziodistal pozisyon açısından iki yapıştırma yöntemi arasında istatistiksel olarak anlamlı bir fark bulunamamış ancak, indirekt yöntemle braketlerin dikey yönde ideale daha yakın bir biçimde konumlandırılabildiği ortaya çıkarılmıştır. ${ }^{48}$

Aguirre ve $a^{42}{ }^{42}$ direkt ve indirekt tekniği braket konumunun doğruluğu yönünden karşılaştırdıkları klinik çalışmalarına alt ve üst ikinci premolarlar arası dişleri dahil etmiştir. Sonuç olarak her iki yapıştırma yöntemiyle de braketlerin \%100 doğru yapıştırılamadığı ortaya konmuştur. Braketlerin dik yön konumu değerlendirildiğinde her iki yapıştırma yöntemi arasında istatistiksel olarak önemli bir fark bulunamamış, ancak indirekt yerleştirilen üst kanin ve direkt yerleştirilen alt ikinci küçük azı braketlerinin dik yön konumunun ideale daha yakın olduğu belirlenmiştir. Braketlerin angulasyonları değerlendirildiğinde indirekt yapıştırılan alt ve üst kanin braketlerinin ideale daha yakın olduğu bulunmuştur. ${ }^{42}$

Hodge ve arkadaşlarının ${ }^{49}$ yapmış olduğu braket konumlarının doğruluğunu araştıran bir başka klinik çalışmada sadece alt ve üst ön 6 diş (kesici dişler ve kanin dişleri) değerlendirilmiştir. Çalışmaya 26 hasta dahil edilmiş ve aynı hastanın iki yarım çenesinde direkt braketleme, diğer iki yarım çenesinde ise indirekt braketleme yapılmıştır. Braketleme öncesi ve sonrası alınan fotoğraflar üzerinde yapılan çizimler kullanılarak ideal pozisyondan sapma miktarları hesaplanmış ve sonuç olarak; braketlerin meziodistal, dik yön konumları ve angulasyonları açısından iki yapıştırma tekniği arasında istatistiksel olarak önemli bir fark olmadığı bulunmuştur. Ancak, üst çenede alt çeneden daha fazla ve braketlerin dik yön konumlarında, meziodistal konumlarından daha fazla hata yapıldığı görülmüştür. ${ }^{49}$

\section{Periodontal dokular üzerine etkileri}

İndirekt yapıştırma tekniğinde klinik aşama sonrasında braketlerin kenarlarından taşan kompozit rezin nedeniyle periodontal dokularda inflamasyon ve plak birikimi gibi durumlarla karşılaşılabilir. Ancak bu durum; braket tabanlarına az miktarda kompozit uygulanması ve taşan kompozitlerin frez yardımıyla temizlenmesi ile giderilebilir. Yapılan çalışmalar teknik uygun şekilde gerçekleştirildiğinde periodontal dokular üzerinde direkt teknik ile benzer etkiler geliştiğini ortaya koymaktadır.

İndirekt ve direkt yapıştırma tekniklerinin periodontal dokular üzerine etkilerini inceleyen bir çalışmada direkt yapıştırma tekniğinde kimyasal sertleşen 'Concise' ve 
'Endur' rezin, indirekt yapıştırma tekniğinin laboratuvar aşamasında karamel, klinik aşamasında ise kimyasal sertleşen 'Auto-Tach' ve 'Endur' rezin kullanılmıştır. Altı aylık inceleme süresi boyunca diş etlerinde meydana gelen değişiklikler değerlendirilmiştir. Genel olarak hastalarda gingivitis meydana gelmiş ancak küçük boyutlu doldurucu parçacıklar içeren kimyasal sertleşen 'Endur' rezin kullanıldığında iki yapıştırma yöntemi arasında istatistiksel açıdan önemli bir fark olmadığı bulunmuştur. ${ }^{10}$

İndirekt ve direkt yapıştırma tekniklerinin diş eti dokuları üzerine etkilerini karşılaştıran 2007 yılında yapılmış bir başka çalışmada da her iki yöntemde de braketlenen segmentlerde 'Diş eti indeksi' skorlarında 6 ay boyunca genel olarak bir artış gözlemlenmiştir. Her iki yöntemde de 6 . ayın sonunda diş etlerinde hafif bir renk değişikliği ve ödemle karakterize hafif bir inflamasyon meydana gelmiştir. Bu iki yapıştırma yönteminin 'Diş eti indeksi' skorları arasındaki fark istatistiksel olarak anlamlı bulunmamıştır. Indirekt ve direkt braketlenen segmentlerde 'Plak indeksi' skorlarında 6 ay boyunca genel olarak bir artış gözlemlenmiştir. Hem indirekt hem de direkt braketlenen dişlerde genel olarak plak birikimi interdental bölgelerde olmuştur. 'Plak indeksi' skorları açısından karşılaştırılan iki yapıştırma yöntemi arasındaki fark istatistiksel olarak anlamlı bulunmamıştır. ${ }^{50}$

\section{Sonuç}

İndirekt yapıştırma tekniğinin en büyük avantajı olarak daha doğru braket pozisyonu sağlaması ve hasta başı çalışma süresinin daha kısa olması gösterilmektedir. Yapılan çalışmalar her iki teknikle de braketlerin \%100 doğru konumlandırılamadığını gösterse de braketlerin laboratuvar ortamında hastadan alınan dental modeller üzerinde konumlandırılması, direkt braketleme yöntemine göre daha az hataya sebep olabilir. Bu toplam tedavi süresi ve randevu sayısını anlamlı ölçüde azaltmasa da özellikle tedavinin bitim aşamasında gerekebilecek ek büküm ve braket pozisyonu değişikliği intiyacını azaltabilir. Ancak indirekt yapıştırma tekniği, hem laboratuvar hem de klinik aşamalarında daha fazla özen ve hassasiyet gerektirmektedir ve maliyeti daha yüksektir. Hekimin bu iki yapıştırma yönteminden hangisini seçeceği; laboratuvar süresi, klinik süresi, maliyet, hasta konforu gibi etkenlere ve kendi kişisel tercihine bağlı olarak değişebilir.

Çıkar çatışması: Yazarlar bu çalışmayla ilgili herhangi bir çıkar çatışmalarının bulunmadığını bildirmişlerdir.

\section{KAYNAKLAR}

1. Sondhi A. Precise bracket placement: effective and efficient indirect bonding. Graber TM, Vanarsdall RL Jr, Vig KWL, eds. Orthodontics: Current Principles and Techniques. 4th edn. St Louis, MO: Elsevier; 2005. p. 661-73.

2. Buonocore MG. A simple method of increasing the adhesion of acrylic filling materials to enamel surfaces. J Dent Res 1955;34:849-53.

3. Silverman E, Cohen M, Gianelly AA, Dietz VS. A universal direct bonding system for both metal and plastic brackets. Am J Orthod Dentofacial Orthop 1972;62:236-44.

4. Buonocore MG. Adhesive sealing of pits and fissures for caries prevention with the use of ultraviolet light. J Am Dent Assoc 1970;80:32430.

5. Weisser JI. A successful method for bonding stainless steel brackets and auxiliaries. J Clin Orthod 1973;7:637-45.

6. Newman GV. Adhesive and orthodontic plastic attachments. Am J Orthod Dentofacial Orthop 1969;56:573-8.

7. Harari D, Aunni E, Gillis I, Redlich M. A new multipurpose dental adhesive for orthodontic use: in vitro bond-strength study. Am J Orthod Dentofacial Orthop 2000;118:307-10.

8. Silverman E, Cohen M. A report on a major improvement in the indirect bonding technique. J Clin Orthod 1975;9:270-6.

9. Thomas RG. Indirect bonding: simplicity in action. J Clin Orthod 1979;13:93-105.

10. Hickham JH. Predictable indirect bonding. J Clin Orthod 1993;27:215-7.

11. White L. A new and improved indirect bonding technique. J Clin Orthod 1999;33:17-23.

12. Zachrisson BU, Büyükyilmaz T. Bonding in orthodontics. Graber TM, Vanarsdall RL Jr, Vig KW, eds. Orthodontics, Current Principles and Techniques, 4th edn. St Louis, MO: Elsevier; 2005. p. 579-659.

13. Zachrisson BU, Brobakken BO. Clinical comparison of direct versus indirect bonding with different bracket types and adhesives. Am J Orthod Dentofacial Orthop 1978;74:62-78.

14. Moskowitz EM, Knight LD, Sheridan JJ, Esmay T, Tovilo K. A new look at indirect bonding. J Clin Orthod $1996 ; 30: 277-81$.

15. Polat $\mathrm{O}$, Karaman $\mathrm{Al}$, Buyukyilmaz $\mathrm{T}$. In vitro evaluation of shear bond strengths and in vivo analysis of bond survival of indirect-bonding resins. Angle Orthod 2004;74:405-9.

16. Keim RG, Gottlieb EL, Nelson AH. 2002 JCO study of orthodontic diagnosis and treatment procedures. Part 1 Results and trends. J Clin Orhod 2002;36:553-68.

17. Milne JW, Andreasen GF, Jakobsen JR. Bond strength comparison: a simplified indirect technique versus direct placement of brackets. Am J Orthod Dentofacial Orthop 1989;96:8-15.

18. McCrostie HS. Indirect bonding simplified. J Clin Orthod 2003;37:248-51.

19. Collins J. A precise and predictable laboratory procedure for indirect bonding. J Clin Orthod 2000;34:702-5.

20. Echarri $P$, Kim T. Double transfer trays for indirect bonding. J Clin Orthod 2004;38:8-13

21. Hiro T, Takemoto K. Resin core indirect bonding system: improvement of lingual orthodontic treatment. J Jpn Orthod Soc 1998;57:8391.

22. Matsuna I, Okuda S, Nodera $Y$. The hybrid core system for indirect bonding. J Clin Orthod 2003;37:160-1.

23. Kyung HM, Park HS, Sung JH. The mushroom bracket positioner for lingual orthodontics. J Clin Orthod 2002;36:320-8.

24. Kim TW. Indirect bonding system in lingual orthodontics. Korean J Orthod 2002;32:38-45

25. Kim TW, Bae GS, Cho J. New indirect bonding method for lingual orthodontics. J Clin Orthod 2000;34:348-50.

26. Kasrovi P, Timmins $S$, Shen A. A new approach to indirect bonding using light-cure composites. Am J Orthod Dentofacial Orthop 1997;6:652-6.

27. Koga M, Watanabe K, Koga T. Quick indirect bonding system (Quick IDBS): an indirect bonding technique using a double-silicone bracket transfer tray. Semin Orthod 2007;13:11-8.

28. Moskowitz EM. Indirect bonding with a thermal cured composite. Semin Orthod 2007;13:69-74

29. Ciuffolo F, Epifania E, Duranti G, De Luca V, Raviglia D, Rezza S, et al. Rapid prototyping: a new method of preparing trays for indirect 
bonding. Am J Orthod Dentofacial Orthop 2006;129:75-7.

30. Castilla AE, Crowe JJ, Moses JR, Wang M, Ferracane JL, Covell DA. Measurement and comparison of bracket transfer accuracy of five indirect bonding techniques. Angle Orthod 2014;84:607-14.

31. Sinha PK, Nanda RS, Ghosh J. A thermal-cured, flouride-releasing indirect bonding system. J Clin Orthod 1995;29:97-100.

32. Read MJF, Pearson Al. A method for light-cured indirect bonding. J Clin Orthod 1998;32:502-3.

33. Klocke A, Shi J, Kahl-Nieke B, Bismayer U. Bond strength with custom base indirect bonding techniques. Angle Orthod 2003;73:176-80.

34. Daub J, Berzins DW, Linn BJ, Bradley TG. Bond strength of direct and indirect bonded brackets after thermocycling. Angle Orthod 2006;76:295-300.

35. Årtun J, Bergland S. Clinical trials with crystal growth conditioning as an alternative to acid-etch enamel pretreatment. Am J Orthod Dentofacial Orthop 1984;85:333-40.

36. Klocke A, Tadic D, Vaziri F, Kahl-Nieke B. Custom base preaging in indirect bonding. Angle Orthod 2004;74:106-11.

37. Hocevar RA, Vincent HF. Indirect versus direct bonding: bond strength and failure location. Am J Orthod Dentofacial Orthop 1988;94:36771.

38. Yi GK, Dunn WJ, Taloumise LJ. Shear bond strength comparison between direct and indirect bonded orthodontic brackets. Am J Orthod Dentofacial Orthop 2003;124:577-81.

39. Linn BJ, Berzins DW, Dhuru VB, Bradley TG. A comparison of bond strength between direct and indirect bonding methods. Angle Orthod 2006;76:289-94.

40. Miles PG, Weyant RJ. A clinical comparison of two chemically-cured adhesives used for indirect bonding. J Orthod 2003;30:331-6.

41. Miles PG, Weyant RJ. A comparison of two indirect bonding adhesives. Angle Orthod 2005;75:1019-23.

42. Aguirre MJ, King GJ, Waldron JM. Assessment of bracket placement and bond strength when comparing direct bonding to indirect bonding techniques. Am J Orthod Dentofacial Orthop 1982;82:269-76.

43. Read MJF, O'Brien KD. A clinical trial of an indirect bonding technique with a visible light- cured adhesive. Am J Orthod Dentofacial Orthop 1990;98:259-62.

44. Miles PG. A comparison of retention rates of brackets with thermally-cured and light-cured custom bases in indirect bonding procedures. Aust Orthod J 2000;16:115-7.

45. Bozelli JV, Bigliazzi R, Barbosa HA, Ortolani CL, Bertoz FA, Faltin Junior K. Comparative study on direct and indirect bracket bonding techniques regarding time length and bracket detachment. Dental Press J Orthod 2013;18:51-7.

46. Thiyagarajah S, Spary DJ, Rock WP. A clinical comparison of bracket bond failures in association with direct and indirect bonding. J Orthod 2006;33:198-204
47. Deahl ST, Salome N, Hatch JP, Rugh JD. Practice-based comparison of direct and indirect bonding. Am J Orthod Dentofacial Orthop 2007; 132:738-42.

48. Koo BC, Chung GH, Vanarsdall RL. Comparison of the accuracy of bracket placement between direct and indirect bonding techniques. Am J Orthod Dentofacial Orthop 1999;116:346-51.

49. Hodge TM, Spary DJ. A randomized clinical trial comparing the accuracy of direct versus indirect bracket placement. J Orthod 2000;31:132-7.

50. Demir D. İndirekt bonding ile yapıştırılan braketlerin bağlanma kuvvetleri üzerine farklı ışık kaynaklarının etkisi: laboratuar ve klinik çalışması [tez]. Adana: Çukurova Üniversitesi; 2007.

\section{Indirect bonding technique in orthodontics}

\section{Abstract}

'Direct Bonding Technique' which allows the fixed orthodontic appliances to be directly bonded to teeth without using bands decreased the clinic time for bracket bonding and increased esthetics and oral hygiene during orthodontic treatment. However, mistakes in bracket positioning were observed due to decreased direct visual sight and access to posterior teeth. 'Indirect Bonding Technique' was developed for eliminating these problems. Initially, decreased bond strength, higher bond failure rate, periodontal tissue irritation, compromised oral hygiene and increased laboratory time were the main disadvantages of this technique when compared to direct bonding. The newly developed materials and modified techniques help to eliminate these negative consequences. Today, the brackets bonded with indirect technique have similar bond strength with brackets bonded directly. Moreover, indirect and direct bonding techniques have similar effects on periodontal tissues. However, indirect bonding technique requires more attention and precision in laboratory and clinical stage, and has higher cost. Orthodontist's preference between these two bonding techniques may differ according to time spent in laboratory and clinic, cost, patient comfort and personal opinion.

KEYwORDS: Dental bonding; orthodontic adhesives; orthodontic brackets 